\title{
Development Characteristics of College Student View on Marriage and Love
}

\author{
Yongmei Hou ${ }^{\mathrm{a}}$, Xin Liu \\ Department of Psychology, Guangdong Medical University, Dongguan524023, Guangdong \\ Province, China \\ a352314640@qq.com
}

Keywords: Views of love and marriage, Undergraduates, Stratified random sampling

\begin{abstract}
Objective: To investigate the characteristics of Views on Love and Marriage in undergraduates, and analyze its influence factors. Methods: Five hundred and five undergraduates who were collected from 7 universities in Guangdong by stratified random sampling method were investigated with Questionnaire of Undergraduates' View on Marriage and Love (CMLCQ) and a self-made general information questionnaire for undergraduates. Result: (1) The total score of CMLCQ and the scores on the factors of erotic choice and marital tendency were better than the average, the scores of the other five factors were in medium level. (2) The girls got significantly higher scores than the boys on the total score and the following four factors of CMLCQ: erotic choice, marital independence, love motivation and marital values $(t=2.408 \sim 6.307, \mathrm{P}<0.05$ ). (3) The non-onlychildren got significantly higher scores than the only-children on the total score and the following four factors of CMLCQ: erotic choice, view of marital role, marital tendency and marital loyalty $(\mathrm{t}=-2.403 \sim-4.160, \mathrm{P}<0.05)$. (4) There were significant differences on the total score and the following 3 factors : erotic choice, marital tendency and marital loyalty in the students with different family economical status. The rich students got lower scores than the students from ordinary or poor families on the total score and the scores of erotic choice and marital loyalty. While the poor students got significantly lower score than those from ordinary or rich families on the factor of marital tendency. (5) The urban students got significantly lower scores than the rural students on the total score and the scores of the following 3 factors : view of marital role, marital tendency and marital loyalty. (6)There was nearly significant difference among the undergraduates with different parental marital relation on the factor of view of marital role. (7) There was nearly significant major differences on the total score and the score of the factor of marital value. Conclusion: The development of each factor of View on Marriage and Love (CMLCQ) is disparate. Undergraduates' marriage concept coexists between modernity and tradition.
\end{abstract}

\section{Introduction}

The view on marriage and love refers to people's basic view on marriage and love relationship, including the 4 aspects of view on love, view on spouse choice, view on love loss and attitude towards sex. View on marriage and love is the view on life and values in marriage and love, with subtle influence on outlook on life and values ${ }^{[1]}$. As social consciousness, view on marriage and love reflects cultural features of society, greatly dependent on social living conditions. Different societies have different views on marriage and love.

College life is the period of individual life outlook establishment, and the critical period of development of the view on marriage and love ${ }^{[2]}$. Under the influence of multiple factors, such as social transformation, lack of family education and school education, popularization of new media, 
western trend of thought (like post-modernism), college student view on marriage and love witnesses various problems ${ }^{[3-6]}$, harmful to physical and mental health and family happiness, and harmonious development of society ${ }^{[7]}$.

Based on the above, we intend to understand the characteristics of development of college student view on marriage and love, and analyze its influencing factors.

\section{Objects and methods}

\subsection{Objects}

We applied stratified random to abstract 570 undergraduates from 7 colleges in Guangdong Province, collecting 505 valid questionnaires, with an effective rate of $88.6 \%$. including 173 boys (34.3\%), 332 girls (65.7\%), 115 freshmen (22.8\%), 123 sophomores (24.4\%), 130 juniors (25.7\%), 137 seniors(27.1\%), 296 urban students(58.6\%), 209 (41.4\%) rural students, 278 (55.0\%) students of arts, 157 (31.1\%) science students, 53 (10.5\%) engineering students, 17 (3.4\%) students of art, 162 only-child (32.1\%), 343 non-only-child (67.9\%), 23 (4.6\%) children of well-to-do families, 399 (79.0\%) of average families and 83 (83.4\%) children of less well-to-do families, 470 (93.1\%) children with their parent marital relationship normal, 7 (1.4\%) children with their parents separated and 28 (5.5\%) children with their parents divorced.

\subsection{Tools}

\subsubsection{Questionnaire of undergraduate view on marriage and love (CMLCQ) [8].}

Compiled by Su Hong, in total 34 entries, divided into the 7 factors of sex choice, role of marriage, marital autonomy, marital tendency, love motive, marital loyalty and value, applying Likert 5-point scoring, including "excellent" as 5, "very good" as 4, "good” as 3, "average” as 2 and "fail" as 1 . The higher the score is, the more conservative the view on marriage and love will be. In this study, the internal consistency coefficient of the 7 factors was $0.6653-0.7704$, the internal consistency coefficient of the total questionnaire was 0.8210 , the retest reliability of each factor after 1 month was $0.8258-0.8435$, the full scale retest reliability after 1 month was 0.8841 .

\subsubsection{Self-made personal general situation questionnaire}

Including the 7 aspects of gender, grade, profession, student source, family economic status, only-child, marital status of parents

\subsection{Methods}

Questionnaires were issued by uniformly trained investigators, the subjects filled in them anonymously.

\subsection{Statistical Analysis}

Applying the parallel input method for data entry; applying Excel input and review, applying SPSS17.0 for statistical analysis; Measurement data applied descriptive statistics, independent sample t test, one-way analysis of variance (ANOVA) for analysis, count data applying $\chi 2$ test analysis.

\section{Results}

\subsection{College student view on marriage and love table total scores and each dimension score}

From Table 1, we can see the scores of college student on the two factors of CMLCQ total scores and sex choice, marital tendency are high, scores of CMLCQ and other 5 factors are moderate. 
Table 1 College student CMLCQ total scores and each dimension

\begin{tabular}{l|l|l|l|l|l|l|l|l}
\hline Factor & $\begin{array}{l}\text { Sex } \\
\text { choice }\end{array}$ & $\begin{array}{l}\text { Marriage } \\
\text { role }\end{array}$ & $\begin{array}{l}\text { Marriage } \\
\text { autonomy }\end{array}$ & $\begin{array}{l}\text { Marriage } \\
\text { inclination }\end{array}$ & $\begin{array}{l}\text { Love } \\
\text { motives }\end{array}$ & $\begin{array}{l}\text { Loyalty } \\
\text { to } \\
\text { marriage }\end{array}$ & $\begin{array}{l}\text { Marital } \\
\text { value }\end{array}$ & Total scores \\
\hline $\mathrm{M}$ & 3.903 & 2.792 & 3.099 & 3.591 & 2.722 & 3.021 & 2.737 & 109.74 \\
\hline $\mathrm{SD}$ & 0.806 & 0.841 & 0.507 & 0.791 & 0.796 & 0.800 & 0.488 & 14.01 \\
\hline
\end{tabular}

\subsection{Gender difference in the view on marriage among college students}

Table 2 shows that girls scores higher than boys scores on the 4 factors of CMLCQ total scores and sex choice, marital autonomy, love motives and marital value, and the difference was statistically significant $(\mathrm{t}=-2.408 \sim-6.307, \mathrm{P}<0.05)$.

Table 2 Boy and girl student scores on the CMLCQ comparison

\begin{tabular}{l|c|c|c|c|c|c}
\hline \multicolumn{1}{c|}{ Dimension } & \multicolumn{2}{c|}{ Male $(\mathrm{n}=173)$} & \multicolumn{2}{c|}{ Female $(\mathrm{n}=332)$} & $\mathrm{t}$ & $P$ \\
\hline Sex choice & $\mathrm{M}$ & $\mathrm{SD}$ & $\mathrm{M}$ & $\mathrm{SD}$ & & \\
\hline Marriage role & 28.65 & 7.10 & 32.57 & 5.64 & -6.307 & $<0.001$ \\
\hline Marriage autonomy & 14.11 & 4.35 & 13.88 & 4.13 & 0.574 & 0.566 \\
\hline Marriage inclination & 18.23 & 4.05 & 17.81 & 3.90 & 1.136 & 0.256 \\
\hline Love m $\square$ tives & 10.32 & 3.32 & 11.19 & 3.08 & -2.930 & 0.004 \\
\hline \begin{tabular}{l} 
Loyalty to marriage \\
\hline Marital value
\end{tabular} & 15.28 & 4.15 & 15.02 & 3.92 & 0.715 & 0.475 \\
\hline $\begin{array}{l}\text { View on marriage } \\
\text { and love total scores }\end{array}$ & 106.54 & 14.52 & 111.41 & 13.46 & -3.759 & $<0.001$ \\
\hline
\end{tabular}

\subsection{Only-child and non-only-child view on marriage and love comparison}

As can be seen from Table 3, the non-only child scores are higher than only-child scores on the 4 factors of CMLCQ total scores, sex choice, marital status, marital tendency and marital loyalty, and the difference was statistically significant $(\mathrm{t}=-2.403 \sim-4.160, \mathrm{P}<0.05)$.

Table 3 Comparison of only-child and non-only-child scores on CMLCQ

\begin{tabular}{|c|c|c|c|c|c|c|}
\hline \multirow[t]{2}{*}{ Dimension } & \multicolumn{2}{|c|}{ Yes } & \multicolumn{2}{|c|}{ No } & \multirow[t]{2}{*}{$\mathrm{t}$} & \multirow[t]{2}{*}{$p$} \\
\hline & $\mathrm{M}$ & SD & $M$ & SD & & \\
\hline Sex choice & 30.02 & 6.81 & 31.79 & 6.20 & -2.890 & 0.004 \\
\hline Marriage role & 13.30 & 4.53 & 14.26 & 4.01 & -2.403 & 0.017 \\
\hline Marriage autonomy & 12.30 & 2.25 & 12.44 & 1.92 & -0.741 & 0.459 \\
\hline Marriage inclination & 17.28 & 4.18 & 18.27 & 3.81 & -2.641 & 0.009 \\
\hline Love motives & 11.25 & 3.28 & 10.72 & 3.13 & 1.737 & 0.083 \\
\hline Loyalty to marriage & 13.98 & 4.35 & 15.63 & 3.72 & -4.160 & $<0.001$ \\
\hline Marital value & 8.16 & 1.55 & 8.23 & 1.43 & -0.508 & 0.612 \\
\hline $\begin{array}{l}\text { View on marriage and love } \\
\text { total scores }\end{array}$ & 106.30 & 15.25 & 111.35 & 13.11 & -3.831 & $<0.001$ \\
\hline
\end{tabular}

\subsection{Comparison between college students of different family economic states in view on marriage} and love

Table 4 shows that college students with different family financial states CMLCQ total scores and sex choice factors are significantly different $(\mathrm{P}=3.505-5.116, \mathrm{P}<0.05)$, and difference in marriages inclination edge is significant $(\mathrm{F}=2.470, \mathrm{P}=0.086)$. 
Table 4 Comparison between college students of different family economic states view on marriage and love

\begin{tabular}{|c|c|c|c|c|c|c|c|c|}
\hline \multirow[t]{2}{*}{ Dimension } & \multicolumn{2}{|c|}{ Wealthy (23) } & \multicolumn{2}{|c|}{ General (399) } & \multicolumn{2}{|c|}{ Poor (83) } & \multirow[t]{2}{*}{$\mathrm{F}$} & \multirow[t]{2}{*}{$p$} \\
\hline & M & SD & $\mathrm{M}$ & SD & M & SD & & \\
\hline Sex choice & 27.30 & 9.41 & 31.51 & 6.19 & 30.94 & 6.40 & 4.808 & 0.009 \\
\hline Marriage role & 13.91 & 6.30 & 14.00 & 4.12 & 13.78 & 3.93 & 0.090 & 0.914 \\
\hline Marriage autonomy & 12.09 & 3.81 & 12.47 & 1.86 & 12.14 & 2.10 & 1.143 & 0.320 \\
\hline Marriage inclination & 17.74 & 4.47 & 18.15 & 3.87 & 17.10 & 4.14 & 2.470 & 0.086 \\
\hline Love motives & 11.35 & 4.33 & 10.81 & 3.14 & 11.14 & 3.08 & 0.629 & 0.534 \\
\hline Loyalty to marriage & 12.52 & 5.10 & 15.23 & 3.93 & 15.25 & 3.80 & 5.116 & 0.006 \\
\hline Marital value & 7.91 & 1.51 & 8.22 & 1.48 & 8.27 & 1.40 & 0.534 & 0.587 \\
\hline $\begin{array}{llr}\text { View } & \text { on marriage } \\
\text { and } & \text { love } & \text { total } \\
\text { scores } & & \\
\end{array}$ & 102.83 & 20.83 & 110.37 & 13.71 & 108.63 & 12.90 & 3.505 & 0.031 \\
\hline
\end{tabular}

Further pair-wise comparison shows that the CMLCQ scores of students of well-to-do families is lower than those of average families $(P=0.012)$, and significantly different in total scores edge from students of poor families ( $\mathrm{P}=0.078)$, scores of view on sex choice of students of well-to-do families are significantly lower students of average families $(P=0.002)$ and students of poor families $(\mathrm{P}=0.016)$. Scores of view on loyalty of students of well-to-do families significant lower than those of average families $(\mathrm{P}=0.002)$ and those of poor families $(\mathrm{P}=0.004)$. Score of students of poor families in marital tendency are significantly lower than those of average families $(\mathrm{P}=$ 0.028).

\subsection{Difference of views on marriage and love of college students of parents with different marital states.}

Table 5 shows score different edge of views on marriage and love of college students of parents with different marital states is significant $(P=0.056)$.

Table 5 CMLCQ score comparison of college students of parents with different marital states

\begin{tabular}{l|c|c|c|c|c|c|c|c}
\hline \multicolumn{1}{c|}{ Dimension } & \multicolumn{2}{c|}{ Normal (470) } & \multicolumn{2}{c|}{ Divorced (28) } & \multicolumn{2}{c|}{ Separated (7) } & F & $p$ \\
\hline & $\mathrm{M}$ & $\mathrm{SD}$ & $\mathrm{M}$ & $\mathrm{SD}$ & $\mathrm{M}$ & $\mathrm{SD}$ & & \\
\hline Sex choice & 31.14 & 6.47 & 31.54 & 6.46 & 35.71 & 2.93 & 1.774 & 0.171 \\
\hline Marriage role & 13.87 & 4.22 & 14.64 & 3.78 & 17.43 & 3.31 & 2.891 & 0.056 \\
\hline Marriage autonomy & 12.38 & 2.04 & 12.61 & 1.69 & 12.57 & 2.70 & 0.190 & 0.827 \\
\hline Marriage inclination & 17.99 & 3.97 & 17.93 & 3.85 & 15.86 & 2.48 & 1.002 & 0.368 \\
\hline Love motives & 10.89 & 3.20 & 11.14 & 2.92 & 9.86 & 3.81 & 0.455 & 0.635 \\
\hline Loyalty to marriage & 15.09 & 4.06 & 15.32 & 3.42 & 15.29 & 2.06 & 0.051 & 0.951 \\
\hline Marital value & 8.21 & 1.48 & 8.25 & 1.35 & 7.71 & 1.11 & 0.414 & 0.662 \\
\hline $\begin{array}{l}\text { Total scores of view } \\
\text { on marriage }\end{array}$ & 109.57 & 14.29 & 111.43 & 10.05 & 114.43 & 4.93 & 0.628 & 0.534 \\
\hline
\end{tabular}

Further pair-wise comparison shows scores on marital role factors of separated parents are higher than those of normal marital relationship $(\mathrm{P}=0.026)$.

\subsection{Comparison of view on marriage and love of college students of different sources}

As can be seen from Table 6, scores of urban students in the 3 factors of CMLCQ total scores and view on marriage role, marital orientation and marital loyalty are significantly lower than those of rural students $(\mathrm{t}=-2.214-3.621$, average $\mathrm{P}<0.05)$ margin is significantly different in sex choice $(\mathrm{t}=-1.799, \mathrm{P}=0.073)$. 
Table 6 CMLCQ score comparison of college students of different origins

\begin{tabular}{|c|c|c|c|c|c|c|}
\hline \multirow[t]{2}{*}{ Dimension } & \multicolumn{2}{|c|}{ City（295） } & \multicolumn{2}{|c|}{ Countryside (210) } & \multirow[t]{2}{*}{$\mathrm{t}$} & \multirow[t]{2}{*}{$p$} \\
\hline & M & SD & M & SD & & \\
\hline Sex choice & 30.79 & 6.59 & 31.84 & 6.20 & -1.799 & 0.073 \\
\hline Marriage role & 13.52 & 4.47 & 14.58 & 3.72 & -2.916 & 0.004 \\
\hline Marriage autonomy & 12.41 & 1.99 & 12.38 & 2.09 & 0.141 & 0.888 \\
\hline Marriage inclination & 17.63 & 4.09 & 18.41 & 3.71 & -2.214 & 0.027 \\
\hline Love motives & 11.08 & 3.12 & 10.62 & 3.26 & 1.581 & 0.114 \\
\hline Loyalty to marriage & 14.57 & 4.14 & 15.86 & 3.68 & -3.621 & $<0.001$ \\
\hline Marital value & 8.12 & 1.51 & 8.33 & 1.39 & -1.601 & 0.110 \\
\hline $\begin{array}{l}\text { Total scores of view on } \\
\text { marriage and love }\end{array}$ & 108.11 & 14.69 & 112.03 & 12.68 & -3.127 & 0.002 \\
\hline
\end{tabular}

\subsection{Difference in grades of scores of college students of view on marriage and love}

Difference in CMLCQ total scores between different grades and scores in each factor is not significant $(\mathrm{F}=0.221-1.752, \mathrm{P}=0.155$ - 0.882).

\subsection{Difference of college students in view on marriage and love}

From Table 7, we can see that there is no significant difference between the scores of CMLCQ and other factors of college students of different majors $(F=0.214-1.752, \mathrm{P}=0.155-0.882)$, but the difference margin in scores of view on marriage values is significant $(F=2.531, \mathrm{P}=0.058$ ).

Table 7 CMLCQ score comparison of college students of different majors

\begin{tabular}{|c|c|c|c|c|c|c|c|c|c|c|}
\hline \multirow[t]{2}{*}{ Dimension } & \multicolumn{2}{|c|}{ Arts(278) } & \multicolumn{2}{|c|}{ Science(157) } & \multicolumn{2}{|c|}{ Engineering (52) } & \multicolumn{2}{|c|}{ Arts (18) } & \multirow[t]{2}{*}{$\mathrm{F}$} & \multirow[t]{2}{*}{$p$} \\
\hline & M & SD & M & SD & M & SD & M & SD & & \\
\hline $\begin{array}{l}\text { Sex choice } \\
\text { view }\end{array}$ & 31.42 & 6.63 & 31.00 & 6.05 & 30.42 & 6.78 & 32.50 & 6.16 & 0.654 & 0.581 \\
\hline $\begin{array}{l}\text { Marital role } \\
\text { view }\end{array}$ & 13.84 & 4.40 & 14.25 & 3.91 & 13.33 & 4.06 & 15.06 & 3.86 & 1.137 & 0.334 \\
\hline $\begin{array}{l}\text { Marriage } \\
\text { autonomy }\end{array}$ & 12.37 & 2.09 & 12.36 & 1.98 & 12.60 & 1.82 & 12.50 & 2.15 & 0.214 & 0.887 \\
\hline $\begin{array}{l}\text { Marriage } \\
\text { inclination }\end{array}$ & 17.92 & 3.97 & 17.78 & 3.97 & 18.37 & 3.86 & 18.78 & 3.99 & 0.557 & 0.644 \\
\hline $\begin{array}{l}\text { Love } \\
\text { motives }\end{array}$ & 11.07 & 3.38 & 10.71 & 2.90 & 10.54 & 3.09 & 10.67 & 2.81 & 0.690 & 0.558 \\
\hline $\begin{array}{l}\text { Marriage } \\
\text { loyalty }\end{array}$ & 15.06 & 4.16 & 15.22 & 3.69 & 14.77 & 4.19 & 15.78 & 3.74 & 0.341 & 0.796 \\
\hline $\begin{array}{l}\text { Marital } \\
\text { values }\end{array}$ & 8.34 & 1.49 & 8.14 & 1.33 & 7.77 & 1.68 & 8.06 & 1.21 & 2.531 & 0.058 \\
\hline $\begin{array}{l}\text { Total scores } \\
\text { of view on } \\
\text { marriage }\end{array}$ & 110.04 & 14.56 & 109.46 & 12.81 & 107.79 & 14.90 & 113.33 & 12.63 & 0.793 & 0.498 \\
\hline
\end{tabular}

Further pair-wise comparison shows scores of students of arts are significantly higher than those of engineering in marital value dimension $(\mathrm{P}=0.010)$.

\section{Discussion}

According to the CMLCQ grading standards ${ }^{[8]}$, college students of this group score high in the 2 factors of CMLCQ sex choice and marital tendency, score moderately in CMLCQ total scores and other 5 factor scores, girls score higher than boys in CMLCQ total scores and the 4 factors of sex choice, marital autonomy, love motivation and marital values, inconsistent with previous findings ${ }^{[3-6]}$. It suggests college students hold the moderation view on marriage and love, neither 
conservative nor radical, influenced by traditional concepts and characterized by modern youth. They have their sexual morality (namely principle for choice of sexual behaviors and objects) relatively conservative, expecting stable marriage. They don't have sexuality simply satisfy physical needs, or financial gain. They regard affection as a necessary basis for sex and view sex as an important element of marriage. It is worth noting that college students score moderately on the role of marriage and love motivation, no longer focusing on prevailing of men over women in marriage, but centering on equality and mutual respect, no longer sitting tight, but imitating the other when necessary. They don't hurry to fall in love in college, or take love as a pastime or curiosity tool, or pursue once for all love, reflecting certain impact of freedom and equality promoted by the market economy. On the other hand, college students (especially girls) tend to accept premarital sex ${ }^{[9]}$. Anyhow, boys are boys, and girls are conservative and cautious, due to the traditional Chinese family education background.

Only-child scores lower than non-only child on the 4 factors of CMLCQ total scores, sex choice, marital role, marital tendency and marital loyalty, prompting the only-child is more inclined to the equal, democratic and independent marriage, consistent with Yan Xiaojun's findings ${ }^{[10]}$. Growing up in the less constrained family environment, the only-child favors individualistic, lacking family and social responsibilities. Constrained from an early age, bound by parents and siblings, the non-only child is responsible and sacrificial.

The difference of view on marriage and love of college students of different majors is not significant, different from the results of previous studies ${ }^{[8,11]}$. Su Hong's research was completed 10 years ago. At that time, the Internet was not popular. College students mainly received their education through classroom learning. Since the humanistic education accepted by different majors were quite different in content and degree, resulting in their obvious differences in ideas and concepts. Today the Internet is popular, making it easier to access information. In addition to classroom learning, college students receive education through broad social practices. College students increasingly involve in social practice, exchanging their majors, and increasingly improving mutual tolerance.

CMLCQ total scores of well-to-do families are lower than those of decent families, and quite significantly different from CMLCQ total scores of poor families. The scores of well-to-do families on sex choice and marital loyalty are significantly lower than those of decent families and poor families. The scores of poor families significantly lower than those of decent families in view on marital tendency, but not significantly from well-to-do families, suggesting the family economic status has significant impact on the view on marriage and love. College students of well-to-do families are open-minded, centering material foundations. They want to explore the world extensively, experiencing life, but not getting married urgently or taking on family obligations in a hurry. College students of less well-to-do families have low martial tendency, probably due to lack of material conditions such as houses and cars, with marital dreams but without marital capacity.

The scores of urban students in the 3 factors of CMLCQ total scores, view on marital role, marital orientation and marital loyalty are significantly lower than those of rural students, consistent with previous research ${ }^{[8]}$, suggesting urban students prefer the modern view on marriage and love based on equality and democracy compared with rural students. The view on marriage and love of rural students is traditional and conservative. Contacting widely, the urban students upgrade their concepts rapidly, advancing with the times. Contacting narrowly, the rural students upgrade their concept slowly. Influenced by traditional family values and ethics, they have their view on marriage and love conservative.

Overall, the marital status of parents has no significant effect on college students in view on marriage and love. But in terms of marital role, scores of college students of parents with normal marital relations are lower than those of parents with normal marital status in the marital role dimension, but without significant difference from those of parents divorced, consistent with research results of $\mathrm{Su} \mathrm{Hong}^{[8]}$, suggesting college students with parents with normal marital relations favor husband and wife relationship based on equality and democracy. The view on 
marriage and love of individuals is deeply influenced by their native families ${ }^{[12]}$. Normal marital relationship of parents and the divorced reflect characteristics and functions of good marriage from the positive and negative prospective, failing to include parents separated since they are in chaos, lacking adequate educational function for their children.

As a whole, the grade difference of college students is nit significant, inconsistent with the results of previous studies ${ }^{[8]}$, suggesting the psychological development of college students lags behind. The period from 18 to 25 is critical for individual mental maturity, intimacy, loneliness prevention ${ }^{[2]}$. Currently, college students have their marriage and love problems common, indicating their marriage psychology is not yet mature. There is no significant difference in grades in terms of marriage and love, showing their psychological quality development is not obvious. On the one hand, they live in a limited and relatively closed campus for a long time, college students lack enough social contact and necessary social analysis skills, and on the other, the colleges lack systematic and gradual psychological quality education for marriage and love.

\section{References}

[1] Arthur S. Reb, Psychology Dictionary [M]. Translated by Li Boshu, Shanghai: Shanghai Translation Publishing House, 1996.765

[2] Erik. Homburger . Erikson, Identity and Life Cycle: A Reissue [M]. New York: Norton. 1979.

[3] Zhang Yaowen, Bi Hongmei, Girl College Student View on Marriage and Love Confusion and Transcendence from the Postmodernist Perspective, Journal of Nanchang Teachers College (Social Science). 2015, 36 (2): 60-64.

[4] Li Longke, Chen Yuqing, Liu Yanfen, Contemporary Master Candidate View on Marriage and Love and Characteristics --- Study on H University Master Candidate View on Marriage and Love research, Postgraduate Education Research, 2014,3 (1): 54-59

[5] Zhao Qinghua, Deng Guoying, Zhou Dong, Zhang Yongxing, Study on Interaction of Medical College Student View on Marriage and Love and Other Values, China Higher Medical Education, 2014, (5): 17-20.

[6] Wang Dazhao, Jin Yan, Bao Jihong, Analysis of Marriage and Love Views of Qinghai College Students and Educational Countermeasures, Journal of Qinghai Normal University (Philosophy and Social Science Edition), 2014, 46 (4): 153-157

[7] Yang Lijuan. Dalian: Marriage and Love Education Course Beginning in College Lecture [EB/OL] http://www. chinapop. gov. cn / cms / export / sites / chinapop / rkxx / gdkx / t20060608_606. htm [2014-7-6].

[8] Su Hong, Study on College Student Marriage and Love View Structure, Characteristics and Influential Factors [D], Southwest University, 2006

[9] Zhang Ka, Zhang Xiaowan, Li Xiujuan, Chen Yuanyuan, Mass Media Background Post-90’s College Student View on Marriage and Love, Journal of Southwest Agricultural University (Social Science Edition) 2013, 10 (2): 152-155.

[10] Yan Xiaojun, Comparison of Views on Marriage and Love Between One-child and Non-only-child College Students, Health Psychology Journal, 2003,11 (2): 81-83.

[11]Su Hong, Ren Yongjin, Study on Characteristics of View on Marriage and Love of College Students, Chinese Sexology, 2008, 17 (6): 15-18.

[12]Ni cols Mi chael P, Schwartz Rich ard C. Family Therapy: Concepts and Methods (M). Boston: Allyn \& Bacon, 2000 